\title{
Особенности секреции про- и противовоспалительных цитокинов in vitro у туберкулинотрицательных пациентов с различными клиническими формами туберкулеза легких
}

ГОУ ВПО "Сибирский государственный медицинский университет Федерального агентства по здравоохранению и социальному развитию": 634050, Томск, Московский тракт, 2

\section{E.G.Churina, O.I.Urazova, V.V.Novitsky, O.V.Voronkova, I.O.Naslednikova, E.L.Nikulina \\ Producation of proinflammatory and anti-inflammatory cytokines in vitro in patients with various clinical variants of pulmonary tuberculosis and negative tuberculin reaction}

\begin{abstract}
Summary
In this article, production of proinflammatory and anti-inflammatory cytokines was investigated in vitro in tuberculin negative patients with infiltrative, disseminated or fibrocavernous pulmonary tuberculosis. Along with basal hypersecretion of IFN- $\gamma$, patterns of change in basal and BCGinduced production of IL-2, IL-4, IL-10 and TGF- $\beta$ related to Th1-dependent and Th2-dependent immune responses have been described in several clinical variants of tuberculosis. Negative tuberculin skin reaction due to Th1-lymphocytes hypoergy was also caused by multidirectional changes in IL-4 and IL-10 production in infiltrative and disseminated pulmonary tuberculosis and by TGF- $\beta$ hypersecretion in patients with disseminated and fibrocavernous pulmonary tuberculosis.

Key words: pulmonary tuberculosis, cytokines production, immune response.
\end{abstract}

\section{Резюме}

В работе исследована продукция про- и противовоспалительных цитокинов in vitro у туберкулинотрицательных пациентов с инфильтративным, диссеминированным и фиброзно-кавернозным туберкулезом легких (ТЛ). Наряду с базальной гиперсекрецией IFN- $\gamma$ описаны варианты изменений базальной и BCG-индуцированной секреции IL-2, IL-4, IL-10 и TGF- $\beta$ при отдельных клинических формах туберкулезной инфекции, характеризующие активность Th1- и Th2-зависимого иммунного ответа. При этом показано, что отрицательная кожная реакция на введение туберкулина в связи с гипоэргией Th1-лимфоцитов обусловливается также разнонаправленными изменениями продукции IL-4 и IL-10 при инфильтративном и диссеминированном ТЛ и гиперсекрецией TGF- $\beta$ у больных диссеминированным и фиброзно-кавернозным ТЛ.

Ключевые слова: туберкулез легких, продукция цитокинов, иммунный ответ.

Туберкулез сегодня является одной из самых серьезных медико-социальных проблем. Среди инфекционных заболеваний туберкулез легких (ТЛ) прочно удерживает одно из ведущих мест по заболеваемости и смертности. Важную роль в повышении заболеваемости туберкулезом играют иммунодефицитные состояния, в т. ч. инфекционной этиологии (при вирусных инфекциях, таких как корь, герпетическая и ВИЧ-инфекция), которые способствуют формированию иммуносупрессии [1-3]. Туберкулезная инфекция протекает достаточно длительное время и также постепенно приводит к истощению пула клеток - участников иммунного ответа $[4,5]$.

Исследование цитокинового профиля имеет большое значение для оценки состояния иммунной системы при заболеваниях различного генеза, в т. ч. при туберкулезе. Важнейшими провоспалительными цитокинами являются интерферон- $\gamma$ (IFN- $\gamma)$ и интерлейкин-2 (IL-2), которые продуцируются T-хелперами 1-го типа (Th1), Т-регуляторными клетками (Treg), естественными киллерами (NK) и активируют пролиферацию, дифференцировку и функции
Т-лимфоцитов, бактерицидные свойства макрофагов. Противоположную роль играют цитокины, обладающие иммуносупрессивными функциями, IL-4, IL-10, трансформирующий фактор роста (TGF- $\beta$ ). Именно им отводится важная роль в реализации механизмов супрессии иммунного ответа при ТЛ. IL-10 и TGF- $\beta$ способны дезактивировать макрофаги против Mycobacterium tuberculosis, снижать чувствительность Т-лимфоцитов к IL-2, а также угнетать продукцию IFN- $\gamma$ и фактора некроза опухолей (TNF- $\alpha$ ) макрофагами. IL-10 и TGF- $\beta$ обладают более выраженным супрессорным эффектом по сравнению с IL-4, эффект которого опосредован активацией T-хелперов 2-го типа (Th2) [6-8].

Целью настоящего исследования явилось изучение уровня базальной и BCG-стимулированной продукции про- и противовоспалительных цитокинов мононуклеарами периферической крови в условиях in vitro у больных инфильтративным, диссеминированным и фиброзно-кавернозным ТЛ с отрицательной реакцией на внутрикожное введение туберкулина. 


\section{Материал и методы}

Были обследованы 23 пациента (13 мужчин и 10 женщин) со впервые выявленным инфильтративным (8 человек), диссеминированным (8) и фибрознокавернозным (7) ТЛ в возрасте от 18 до 55 лет. Контрольную группу составили 10 здоровых доноров с аналогичными поло-возрастными характеристиками. Всем обследованным проводилась внутрикожная проба Манту с 2 ТЕ (туберкулиновыми единицами). Результат пробы Манту оценивался через 72 ч путем измерения размера инфильтрата в миллиметpax.

Материалом исследования служили мононуклеары периферической крови, взятой утром натощак из локтевой вены, до начала проведения курса специфической противотуберкулезной терапии. Мононуклеары периферической крови выделяли методом градиентного центрифугирования. Культивирование клеток проводили в полной питательной среде, состоящей из среды RPMI-1 640 (90\%), инактивированной телячьей сыворотки (10\%), L-глутамина (0,3 мг / мл), гентамицина (100 мкг / мл), HEPES (2 ммоль / мл). Количество лимфоцитов в суспензии стандартизировали до $2,5 \times 10^{6} /$ мл. Определяли базальный и стимулированный вакциной BCG (50 мкг / мл) уровень продукции цитокинов IFN- $\gamma$, IL-2, IL-4, IL-10, TGF- $\beta$. Содержание цитокинов в культуральных супернатантах оценивали с помощью твердофазного иммуноферментного анализа (ELISA) в соответствии с инструкцией, прилагаемой производителями. Исследование проводили с использованием наборов ООО "Протеиновый контур" (Росссия) - для определения IL-2, ЗАО "ВекторБест" (Россия) - для определения IL-4, IL-10, и BCM Diagnostics (США) - для определения TGF- $\beta$ и IFN- $\gamma$.

Статистическую обработку полученных результатов проводили с помощью программы Statistica 6,0. Для оценки нормальности распределения в выборке применяли критерий Колмогорова-Смирнова. Для каждой выборки, распределение которой отличалось

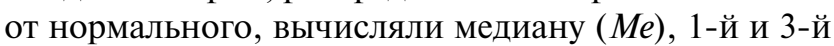

квартили $\left(\mathrm{Q}_{25 \%}, \mathrm{Q}_{75 \%}\right)$. Проверку достоверности различий для зависимых выборок осуществляли с помощью непараметрического критерия Уилкоксона, для независимых выборок - с использованием непараметрического критерия Манна-Уитни. Различие 2 сравниваемых величин считали достоверным при уровне значимости $<5 \%(p<0,05)$.

\section{Результаты и обсуждение}

Как показало проведенное нами исследование, у туберкулинотрицательных пациентов с инфильтративной и диссеминированной формами ТЛ отмечается повышение продукции провоспалительных цитокинов - IL-2 и IFN- $\gamma$ - относительно соответствующих показателей у здоровых индивидов. У больных с фиброзно-кавернозной формой ТЛ уровень секреции IFN- $\gamma$ превышает контрольные значения, а уровень образования IL-2 - существенно ниже (практически в 4 раза), чем у здоровых лиц (табл. 1.).

При инкубации клеток с вакцинным штаммом BCG отмечался прирост уровня продукции IFN- $\gamma$ по сравнению с базальной секрецией цитокина как в контрольной группе (в 2 раза), так и у пациентов с ТЛ (в 1,5-4,1 раза). Со стороны IL-2 картина была иной - 3-кратный прирост уровня образования данного цитокина выявлялся лишь у здоровых лиц, в то время как у пациентов с диссеминированным и фиброзно-кавернозным ТЛ увеличения секреции IL-2 не обнаруживалось, а у пациентов с инфильтративной формой заболевания уровень продукции данного цитокина достоверно (в 5,4 раза) снижался (табл. 1).

Изменение интенсивности продукции противовоспалительных цитокинов, обладающих иммуносупрессивными функциями, носило еще более неоднозначный характер (табл. 2). Так, у больных инфильтративным ТЛ устанавливалось угнетение базальной продукции IL-4 на фоне увеличения секреции IL-10, а у больных диссеминированным ТЛ - наоборот, дефицит базальной секреции IL-10 при одновременном повышении образования IL-4. Уровень секреции данных цитокинов у больных

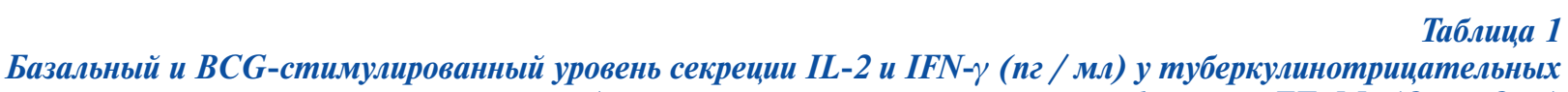
больных с различными клиническими формами ТЛ, $\mathrm{Me}\left(Q_{25 \%}: Q_{75 \%}\right)$

\begin{tabular}{|c|c|c|c|c|c|}
\hline \multirow{2}{*}{\multicolumn{2}{|c|}{$\begin{array}{c}\text { Концентрация } \\
\text { цитокина, пг / мл }\end{array}$}} & \multicolumn{4}{|c|}{ Группы обследованных } \\
\hline & & \multirow{2}{*}{$\begin{array}{c}\text { Здоровые } \\
\text { доноры } \\
22,65(9,32: 120,16)\end{array}$} & \multirow{2}{*}{$\begin{array}{c}\text { Больные } \\
\text { инфильтративным ТЛ } \\
29,47(23,56: 55,31) ; \\
p_{1}<0,05, p_{2}<0,05\end{array}$} & \multirow{2}{*}{$\begin{array}{c}\text { Больные } \\
\text { диссеминированным Тл } \\
27,54(9,95: 53,80) ; \\
p_{1}<0,05\end{array}$} & \multirow{2}{*}{$\begin{array}{c}\text { Больные фиброзно- } \\
\text { кавернозным ТЛ } \\
5,57(4,45: 6,76) ; \\
<0,005, p_{3}<0,005, p_{4}<0,001\end{array}$} \\
\hline IL-2 & $\begin{array}{l}\text { Спонтанная } \\
\text { (базальная) }\end{array}$ & & & & \\
\hline & $\begin{array}{l}\text { При инкубации } \\
\text { клеток с ВСG }\end{array}$ & $\begin{array}{c}69,34(14,51: 165,87) ; \\
p_{2}<0,05\end{array}$ & $\begin{array}{c}5,46(4,43: 30,33) \\
p_{1}<0,001, p_{2}<0,005\end{array}$ & $\begin{array}{l}28,72(15,69: 42,34) \\
p_{1}<0,005, p_{3}<0,005\end{array}$ & $\begin{array}{c}7,73(1,73: 13,71) ; \\
p_{1}<0,001, p_{3}<0,005, p_{4}<0,001\end{array}$ \\
\hline \multirow[t]{2}{*}{ IFN- $\gamma$} & $\begin{array}{l}\text { Спонтанная } \\
\text { (базальная) }\end{array}$ & $31,92(16,35: 40,66)$ & $\begin{array}{c}141,48(123,97: 159,73) ; \\
p_{1}<0,001\end{array}$ & $\begin{array}{c}139,24(119,08: 142,02) ; \\
p_{1}<0,001\end{array}$ & $\begin{array}{c}46,65(42,16: 52,71) ; \\
p_{1}<0,05, p_{3}<0,001, p_{4}<0,005\end{array}$ \\
\hline & $\begin{array}{l}\text { При инкубации } \\
\text { клеток с ВСG }\end{array}$ & $\begin{array}{c}60,09(50,94: 85,25) \\
p_{2}<0,05, p_{2}<0,05\end{array}$ & $\begin{array}{c}206,46(189,47: 252,57) \\
p_{1}<0,001, p_{2}<0,005\end{array}$ & $\begin{array}{c}573,55(341,08: 610,01) \\
p_{1}<0,001, p_{2}<0,001 \\
p_{3}<0,005\end{array}$ & $\begin{array}{c}104,94(89,68: 115,13) ; \\
p_{1}<0,005, p_{2}<0,005, p_{3}<0,05, \\
p_{4}<0,005\end{array}$ \\
\hline
\end{tabular}

Примечание: $p_{1}$ - достоверность различий показателей по сравнению с их значениями у здоровых доноров; $p_{2}$ - достоверность различий показателей по сравнению с базальным уровнем секреции цитокина; $p_{3}$ - достоверность различий показателей по сравнению с их значениями у больных инфильтративным ТЛ; $p_{4}-$ достоверность различий показателей по сравнению с их значениями у больных диссеминированным ТЛ. 
Базальный и ВСG-стимулированный уровень секреции IL-4, IL-10 и TGF- $\beta$ (nг / мл) у туберкулинотрицательных больных с различныли клиническими формами ТЛ, Ме $\left(Q_{25 \%}: Q_{75 \%}\right)$

\begin{tabular}{|c|c|c|c|c|c|}
\hline \multirow{2}{*}{\multicolumn{2}{|c|}{$\begin{array}{l}\text { Концентрация } \\
\text { цитокина, пг / мл }\end{array}$}} & \multicolumn{4}{|c|}{ Группы обследованных } \\
\hline & & \multirow{2}{*}{$\begin{array}{c}\text { Здоровые } \\
\text { доноры } \\
39,99(21,143: 55,096)\end{array}$} & \multirow{2}{*}{$\begin{array}{c}\text { Больные } \\
\text { инфильтративным ТЛ } \\
26,02(16,15: 48,33) ; \\
p_{1}<0,05\end{array}$} & \multirow{2}{*}{$\begin{array}{c}\text { Больные } \\
\text { диссеминированным ТЛ } \\
57,94(36,49: 70,51) ; \\
p_{1}<0,05, p_{3}<0,05\end{array}$} & \multirow{2}{*}{$\begin{array}{c}\text { Больные фиброзно- } \\
\text { кавернозным ТЛ } \\
31,85(18,02: 109,17)\end{array}$} \\
\hline IL-4 & $\begin{array}{l}\text { Спонтанная } \\
\text { (базальная) }\end{array}$ & & & & \\
\hline & $\begin{array}{l}\text { При инкубации } \\
\text { клеток с ВСG }\end{array}$ & $43,68(26,05: 68,64)$ & $\begin{array}{l}10,72(9,29: 46,03) \\
p_{1}<0,005, p_{2}<0,05\end{array}$ & $\begin{array}{c}59,16(43,27: 209,01) \\
p_{1}<0,05, p_{3}<0,005\end{array}$ & $\begin{array}{c}40,09(32,74: 72,52) \\
p_{3}<0,05\end{array}$ \\
\hline \multirow[t]{2}{*}{ IL-10 } & $\begin{array}{l}\text { Спонтанная } \\
\text { (базальная) }\end{array}$ & $25,85(22,12: 33,78)$ & $\begin{array}{c}48,29(33,02: 54,56) \\
p_{1}<0,05\end{array}$ & $\begin{array}{l}16,48(6,73: 19,37) \\
p_{1}<0,005, p_{3}<0,005\end{array}$ & $\begin{array}{c}20,89(11,63: 39,05) \\
p_{3}<0,005\end{array}$ \\
\hline & $\begin{array}{l}\text { При инкубации } \\
\text { клеток с ВСG }\end{array}$ & $\begin{array}{c}156,85(66,58: 202,24) \\
p_{2}<0,05, p_{2}<0,001\end{array}$ & $\begin{array}{c}63,93(54,06: 78,42) \\
p_{1}<0,005, p_{2}<0,05\end{array}$ & $\begin{array}{c}33,77(22,24: 92,03) ; \\
p_{1}<0,001, p_{2}<0,005, p_{3}<0,05\end{array}$ & $\begin{array}{c}26,64(10,81: 42,58) ; \\
p_{1}<0,001, p_{3}<0,05, p_{4}<0,05\end{array}$ \\
\hline \multirow[t]{2}{*}{ TGF- $\beta$} & $\begin{array}{l}\text { Спонтанная } \\
\text { (базальная) }\end{array}$ & $934,25(746,62: 1487,26)$ & $907,08(516,64: 1250,17)$ & $\begin{array}{c}1459,94(750,02: 2466,27) \\
p_{1}<0,05, p_{3}<0,05\end{array}$ & $\begin{array}{c}1360,71(1097,73: 2000,68) ; \\
p_{1}<0,05, p_{3}<0,05\end{array}$ \\
\hline & $\begin{array}{l}\text { При инкубации } \\
\text { клеток с ВСG }\end{array}$ & $997,26(500,08: 1412,62)$ & $833,66(207,43: 960,06)$ & $\begin{array}{c}735,09(623,71: 807,05) \\
p_{1}<0,05, p_{2}<0,05\end{array}$ & $\begin{array}{c}1345,47(721,82: 1696,08) ; \\
p_{3}<0,05, p_{4}<0,05\end{array}$ \\
\hline
\end{tabular}

Примечание: $p_{1}$ - достоверность различий показателей по сравнению с их значениями у здоровых доноров; $p_{2}$ - достоверность различий показателей по сравнению с базальным уровнем секреции цитокина; $p_{3}$ - достоверность различий показателей по сравнению с их значениями у больных инфильтративным ТЛ; $p_{1}$ - достоверность различий показателей по сравнению с их значениями у больных диссеминированным ТЛ.

с фиброзно-кавернозным ТЛ сохранялся без видимых изменений.

После инкубации клеток с ВСG у здоровых доноров наблюдался 6-кратный прирост уровня секреции IL-10, тогда как у пациентов с ТЛ эффект стимуляции не был столь значительным. Кроме того, у больных инфильтративным ТЛ уровень секреции IL-4 при культивировании мононуклеарных лейкоцитов c BCG, напротив, оказался ниже показателя его базальной продукции в 2,4 раза (табл. 2). Со стороны образования TGF- $\beta$ in vitro различия между группами исследования были иными. Отмечалось существенное увеличение уровня спонтанной продукции TGF- $\beta$ у пациентов с диссеминированным и фиброзно-кавернозным ТЛ. При этом у здоровых доноров и больных инфильтративным и фиброзно-кавернозным ТЛ вакцина BCG не оказывала стимулирующего эффекта в отношении секреции TGF- $\beta$, а у больных диссеминированным ТЛ - угнетала ее (табл. 2).

В иммунопатогенезе ТЛ защитную роль играют Th1-лимфоциты, секретирующие IFN- $\gamma$, TNF- $\alpha$ и IL-2, тогда как секреция IL-4, IL-10 и TGF- $\beta$ Th2лимфоцитами и (избыточная) Treg-клетками, напротив, способствует развитию и хроническому течению заболевания. Согласно Th1/Th2-парадигме, невозможность элиминации Mycobacterium tuberculosis из организма может быть связана с неадекватным уровнем реагирования клеточного звена иммунитета, т. е. преимущественной реализацией иммунного ответа по гуморальному типу [9].

Включение в исследование туберкулинотрицательных пациентов было обусловлено тем, что при туберкулиновой анергии механизм неэффективного иммунного ответа состоит, по-видимому, в нарушении баланса продукции как Th1-, так и Th2-зависимых иммунорегуляторных цитокинов. Следует отметить, что отрицательная реакция Манту у пациентов с ТЛ является прогностически неблагоприятным признаком и способствует развитию бактериемии, диссеминации инфекции, что приводит к формиро- ванию более тяжелых клинических форм заболевания, как правило, протекающих на фоне выраженного вторичного иммунодефицита и устойчивых к действию противотуберкулезных препаратов [5, $10,11]$.

Обнаруженное нами увеличение базальной и BCG-индуцированной продукции IFN- $\gamma$ у туберкулинотрицательных пациентов с инфильтративной, диссеминированной и фиброзно-кавернозной формами ТЛ является универсальной защитной реакцией иммунной системы против Mycobacterium tuberculosis и может указывать на интерфероногенную активность возбудителя $[12,13]$. В виду того, что уровень IFN- $\gamma$ в плазме крови у больных туберкулезом в активную фазу заболевания значительно увеличивается, большинство авторов склонно считать это показателем активности специфического воспаления [8, 14-16]. IFN- $\gamma$ секретируют Th1- и CD8+-T-лимфоциты, а также $\gamma \mathrm{d}-\mathrm{T}$-клетки, NK- и NKT-лимфоциты [2]. Роль цитокина в антимикобактериальном иммунитете обусловливается его активирующим влиянием на фагоцитарную активность макрофагов и цитотоксичность самих CD8+-лимфоцитов и NK-клеток [17]. Он играет ведущую роль в формировании гранулемы в ткани легкого посредством индукции экспрессии адгезивных молекул и хемокинов, необходимых для рекрутирования моноцитов / макрофагов в очаг воспаления [12].

Зарегистрированное у туберкулинотрицательных пациентов с инфильтративной и диссеминированной формами заболевания повышение базальной продукции IL-2 относительно соответствующих показателей у здоровых лиц также является признаком опосредованной инфектогеном активации иммунной системы. Снижение уровня секреции IL-2 у больных фиброзно-кавернозным ТЛ и отсутствие увеличения продукции данного цитокина в ответ на действие BCG характеризует гипоэргию Th1-зависимого ответа, возможно, вследствие функционального истощения клеток или иммуносупрессорного 
влияния цитокинов, обладающих противовоспалительной активностью.

Многочисленными экспериментальными исследованиями показано, что недостаточная продукция IL-2 ведет к неспособности организма ограничивать рост и размножение внутриклеточных микобактерий, в связи с этим заболевание протекает тяжело, нередко с осложнениями, и имеет неблагоприятный исход. В то же время повышенный уровень спонтанной и индуцированной продукции IFN- $\gamma$ и IL-2 предопределяет благоприятный исход туберкулезного процесса [7].

Известно, что высокий уровень образования TGF- $\beta$ в организме имеет принципиальное значение для перехода острой воспалительной реакции в хроническую форму. По-видимому, этим объясняется высокий уровень образования цитокина in vitro в группе больных фиброзно-кавернозным ТЛ. Гиперпродукция TGF- $\beta$ устанавливалась также при диссеминированной форме заболевания, однако при действии BCG уровень секреции фактора снижался, что является показателем истощения функционального резерва TGF- $\beta$-продуцирующих клеток (макрофаги, Treg, $\gamma$ d-Т-лимфоциты). В целом полученные результаты могут свидетельствовать о том, что TGF- $\beta$ является ключевым цитокином в формировании и реализации механизмов иммуносупрессии у туберкулинотрицательных пациентов с фибрознокавернозным ТЛ, хотя при отрицательной реакции Манту нельзя также исключить заболевание туберкулезом на фоне исходной супрессии иммунного ответа.

Что касается диссеминированной формы ТЛ, то супрессия Th1-зависимого иммунного ответа у данной группы больных (по результатам оценки BCGиндуцированной секреции IL-2), как показывают результаты исследования, может быть обусловлена гиперсекрецией не только TGF- $\beta$, но и IL-4. Из данных литературы следует, что диссеминация Mycobacterium tuberculosis в ткани легких сопровождается IL-4-опосредованным запуском каскада иммунологических реакций гуморального типа и увеличением антителопродукции, что приводит к неконтролируемому течению иммунопатологического процесса, утяжеляет клиническое течение заболевания и способствует деструктивным изменениям и некрозу легких [2].

Вместе с этим, у больных инфильтративным ТЛ выраженное угнетение BCG-индуцированной секреции IL-2 in vitro сочеталось с гипосекрецией IL-4 в условиях высокой базальной продукции IL-10, уровень образования которого при действии на клетки BCG еще более увеличивался. Показано, что IL-10 является универсальной иммунорегуляторной биомолекулой и в зависимости от клеточного окружения может выполнять функцию как супрессора, так и активатора иммунных реакций. Однако большинство исследователей склонно расценивать гиперпродукцию IL-10 как фактор неблагоприятного прогноза инфекционного процесса, учитывая его способность подавлять секреторную активность
Th1-лимфоцитов, продукцию провоспалительных цитокинов и реактивных интермедиатов кислорода и азота моноцитами и макрофагами, дифференцировку моноцитов в тканевые макрофаги и дендритные клетки и антиген-представляющую функцию последних $[2,8]$.

Таким образом, становится очевидным, что причиной формирования вторичной иммунологической недостаточности при ТЛ может быть индуцированная возбудителем поляризация иммунного ответа в направлении Th2. Вирулентные штаммы Mycobacterium tuberculosis способны прямо или опосредованно, через стимуляцию продукции иммуносупрессорных цитокинов, подавлять функции Тh1-лимфоцитов и антиген-презентирующих клеток, усугубляя иммунную недостаточность и детерминируя неблагоприятный прогрессирующий характер течения ТЛ [11, 18]. При этом нельзя четко разграничить значение биологических свойств Mycobacterium tuberculosis и иммунной системы макроорганизма в формировании иммунного ответа. Исход туберкулезной инфекции, с одной стороны, определяется вирулентными свойствами возбудителя, с другой - адекватным (в т. ч. генетически детерминированным) противоинфекционным ответом со стороны иммунной системы. Ключевым моментом, определяющим исход данной патологии, является баланс продукции про- и противовоспалительных цитокинов иммунокомпетентными клетками [1].

\section{Заключение}

1. У туберкулинотрицательных пациентов с инфильтративной и диссеминированной формами заболевания отмечается повышение продукции ведущих провоспалительных цитокинов - IL-2 (базальной) и IFN- $\gamma$ (базальной и BCG-индуцированной) - относительно соответствующих показателей у здоровых индивидов. У больных фиброзно-кавернозным ТЛ уровень секреции IL-2, напротив, ниже, чем у здоровых лиц, что свидетельствует об угнетении Th1-ответа.

2. Базальная гиперсекреция IL-4 (при диссеминированном TЛ), IL-10 (при инфильтративном TЛ) и TGF- $\beta$ (при фиброзно-кавернозном и диссеминированном ТЛ) характеризуют активацию гуморального иммунного ответа, что может быть причиной деструктивных изменений в легких и тяжелого течения инфекционного процесса, а при фиброзно-кавернозном туберкулезе - иметь принципиальное значение для перехода острой воспалительной реакции в хроническую.

3. В основе туберкулиновой анергии при ТЛ лежит дисбланс секреции как Th1-зависимых, так и Th2-зависимых цитокинов. Она сопряжена с низкой реактивностью Тh1-лимфоцитов (снижением резерва секреции IL-2) в условиях реализации иммуносупрессорного эффекта гиперсекреции IL-10 (в сочетании с гипопродукцией IL-4) при инфильтративной и IL-4, TGF- $\beta$ (в сочетании с гипопродукцией IL-10) при диссеминированных 
формах заболевания. У больных фиброзно-кавернозным ТЛ отрицательная проба Манту связана с гипоэргией Тh1-лимфоцитов, которая опосредована TGF- $\beta$.

Работа выполнена при финансовой поддержке Федерального агентства по науке и образованию в рамках ФЦП "Научные и научно-педагогические кадры инновационной России на 20092013" и одобрена этическим комитетом ГОУ ВПО "Сибирский государственный медицинский университет Федерального агентства по здравоохранению и социальному развитию".

\section{Литература}

1. Еремеев В.В., Майоров К.Б. Взаимодействие макрофагмикобактерия в процессе реакции микроорганизма на туберкулезную инфекцию. Пробл. туб. 2002; 3: 54-57.

2. Чепель Э., Хейни М., Мисбах С., Сновден Н. Основы клинической иммунологии: Пер. с англ. 5-е изд. М.: ГЭОТАР-Медиа; 2008.

3. Maher D., Raviglione M. Global epidemiology of tuberculosis. Clin. Chest Med. 2005; 26: 167-169.

4. Воронкова О.В., Уразова О.И., Новицкий В.В., Стрелис A.К. Иммунопатология туберкулеза легких. Томск: Изд-во Томск. ун-та; 2007.

5. Ерохин В.В., Земскова З.С. Современные представления о туберкулезном воспалении. Пробл. туб. 2003; 3: $11-21$.

6. Рыдловская А.В., Симбирцев А.С. Функциональный полиморфизм TNF- $\alpha$ и патология. Цитокины и воспаление 2005; 4 (3): 4-9.

7. Салина Т.Ю., Морозова Т.И. Продукция ИФН- $\gamma$ мононуклеарными клетками крови больных при разных типах течения туберкулезного процесса. Проблемы туберкулеза и болезней легких 2004; 10: 19-21.

8. Шкарин А.В., Белоусов С.С., Аникина О.А. Уровень цитокинов в плазме крови у больных активным инфильтративным туберкулезом легких. Пробл. туб. 2008; 8: $34-38$.

9. Co D.O., Hogan L.H., Kim S.I., Sandor M. Mycobacterial granulomas: keys to a long-lasting host-pathogen relationship. Clin. Immunol. 2004; 113 (2): 130-136.

10. Онищенко Г.Г. Эпидемическая ситуация в Российской Федерации и меры по ее стабилизации. Проблемы туберкулеза и болезней легких 2003; 11: 4-9.
11. Pedroza-Gonzalez A., Garcia-Romo G.S., Aguilar-Leon D. et al. In situ analysis of lung antigen-presenting cells during murine pulmonary infection with virulent Mycobacterium tuberculosis. Int. J. Exp. Pathol. 2004; 85 (3): 135-145.

12. Салина Т.Ю., Морозова Т.И. Интерферон- $\gamma$ и IGG-антитела к Mycobacterium tuberculosis в сыворотке крови больных активным туберкулезом легких. Пробл. туб. 2004; 11: 43-45.

13. Сахарова И.Я., Ариэль Б.М., Скворцова Л.А. и др. Показатели иммунитета и биологические свойства микобактерий при инфильтративном туберкулезе легких. Пробл. туб. 2005; 11: 14-18.

14. Гунтупова Л.Д., Борисов С.Е., Купавцева Е.А. и др. Цитокиновый профиль при гранулематозных болезнях легких. Пробл. туб. 2006; 6: 10-13.

15. Pereira C.B., Palaci M., Leite O.H. et. al. Interferon- $\gamma-$ Receptor deficiency in an infant with fatal bacille CalmetteGuerin infection. Microb. Infect. 2004; 6: 25-33.

16. Taramelli D., Malabarba M.G., Sala G. et al. Production of cytokines by alveolar and peritoneal macrophages stimulated by Aspergillus fumigatus conidia or hyphae. J. Med. Vet. Mycol. 1996; 34 (1): 49-56.

17. Новицкий В.В., Синицина В.А., Воронкова О.В. и др. Цитокинпродуцирующая активность мононуклеарных лейкоцитов периферической крови у больных туберкулезом легких до лечения и на фоне химиотерапии. Пробл. туб. 2005; 6: 39-42.

18. Quesniaux V., Fremond C., Jacobs M. et al. Toll-like receptor pathways in the immune responses to mycobacteria. Microb. Infect. 2004; 6 (10): 946-959.

\section{Информация об авторах}

Чурина Елена Георгиевна - к. м. н., докторант кафедры патофизиологии ГОУ ВПО СибГМУ, тел.: (3822) 526325; 913-806-07-00; факс: (3822) 51-29-90; e-mail: lena1236@yandex.ru

Уразова Ольга Ивановна - д. М. н., проф. кафедры патофизиологии ГОУ ВПО СибГМУ; тел.: (3822) 52-63-25, факс: (3822) 51-29-90

Новицкий Вячеслав Викторович - акад. РАМН, д. М. Н., проф., зав. кафедрой патофизиологии гОУ ВПО СибГМУ; тел.: (3822) 52-63-25, факс: (3822) 51-29-90

Колосова Анна Евгеньевна - аспирант кафедры патофизиологии гоу ВПО СибГМУ; тел.: (3822) 52-63-25, факс: (3822) 51-29-90

Воронкова Ольга Владимировна - д. м. н., проф. кафедры патофизиологии ГОУ ВПО СибГМУ; тел.: (3822) 52-63-25, факс: (3822) 51-29-90 Наследникова Ирина Олеговна - д. м. н., проф. кафедры патофизиологии ГОУ ВПО СибГМУ; тел.: (3822) 52-63-25, факс: (3822) 51-29-90

Никулина Евгения Леонидовна - аспирант кафедры патофизиологии гОУ ВПО СибГМУ; тел.: (3822) 52-63-25, факс: (3822) 51-29-90

Поступила 24.05.10 (с) Коллектив авторов, 2010 УДК 616.24-002.5-092:612.017.01 